\title{
Review Article \\ Clinical Biomarkers and Pathogenic-Related Cytokines in Rheumatoid Arthritis
}

\author{
Xiaoyin Niu and Guangjie Chen \\ Department of Immunology and Microbiology, Shanghai Jiao Tong University School of Medicine, \\ Shanghai Institute of Immunology, 280 South Chongqing Road, Shanghai 200025, China
}

Correspondence should be addressed to Guangjie Chen; guangjie_chen@163.com

Received 23 June 2014; Revised 6 August 2014; Accepted 6 August 2014; Published 21 August 2014

Academic Editor: Xiao-Feng Yang

Copyright (c) 2014 X. Niu and G. Chen. This is an open access article distributed under the Creative Commons Attribution License, which permits unrestricted use, distribution, and reproduction in any medium, provided the original work is properly cited.

Rheumatoid arthritis (RA) is a common autoimmune disease with unknown etiology and pathogenesis. Although major therapeutic advances have been made in recent years, there is no cure for the disease. Current medications mainly reduce inflammation in order to relieve pain and slow joint damage, but many have potentially serious side effects. Therefore, to find specific biomarkers will benefit both RA patients to find relief from the disease and physicians to monitor the disease development. A number of biomarkers have been discovered and used clinically, and others are still under investigation. The autoantibodies, which are widely used in diagnosis and prognosis, novel biomarkers, which reflect clinical disease activity, and newly found biomarkers and pathogenicrelated cytokines are discussed in this review.

\section{Introduction}

Rheumatoid arthritis (RA) is a chronic inflammatory disease of polyarticular arthritis affecting approximately $1 \%$ of adults worldwide $[1,2]$. It typically leads to deformity and destruction of the joints and systemic disorders throughout the body as well. Although the etiology and pathogenesis of RA remain unknown, immunological hyperreactivity caused by large numbers of $\mathrm{T}$ cells, mostly CD4, and plasma cells is generally considered to be important to contribute its development. The clinical diagnosis of RA is based on several criteria, including physical symptoms, joint radiographs, and serological tests [3]. In the ACR/EULAR 2010 classification criteria, "definite RA" is defined based on the confirmed presence of synovitis in at least 1 joint, absence of an alternative diagnosis that better explains the synovitis, and achievement of a total score of 6 or greater (of a possible 10) from the individual scores in 4 domains: number and site of involved joints (score range $0-5$ ), serologic abnormality (score range $0-3$ ), elevated acute-phase response (score range $0-1$ ), and symptom duration (2 levels; range 0-1) [3].

Multiple studies have revealed RA-related autoantibodies and numerous biomarkers including cytokines/chemokines as well as erythrocyte sedimentation rate (ESR) and C-reactive protein (CRP) orchestrate pathological processes in RA [4-6]. During the course of the disease, RA patients need to be diagnosed very early, possibly before diagnostic criteria are fulfilled or maybe even before clinical symptoms are apparent. Early identification of patients with RA will help improve clinical outcomes with early treatments. Then, markers of disease activity and severity are needed. Finally, screen tests for prediction of response to therapy and progression of the diseases are also necessary.

A biomarker, also known as biological marker, generally refers to a measured characteristic which may be used as an indicator of some biological state or condition. This term occasionally refers to a substance whose presence indicates the existence of living organisms. Biomarkers play pivotal roles in disease diagnosis and interventions at early stage and are also helpful in knowing the state of treatment and how body is acting or responding to the medication. Therefore, exploring and measuring biologic markers in blood or in joint fluids may serve as not only indicators of diagnosis but also indicators of prognosis and the subsequent response to therapy. A good biomarker can be used to measure the disease progress and the treatment effectiveness. It is a parameter 
which can be chemical, physical, or biological. Here, we discuss the biomarkers and pathogenic-related cytokines involved in clinic, pathogenesis, and prospection in RA.

\section{Clinical Biomarkers}

The biomarkers currently used for the diagnosis of RA are mostly clinical. Now there are several useful clinical biomarkers, including various autoantibodies, such as rheumatoid factors (RF), anti-perinuclear factor (APF), antikeratin antibodies (AKA), anti-filaggrin antibodies (AFA), and anti-cyclic citrullinated peptide antibodies (anti-CCP). Erythrocyte sedimentation rate (ESR) and C-reactive protein (CRP) also have associations with RA [7].

2.1. Autoantibodies as Clinical Biomarkers. Rheumatoid factor (RF), an antibody to the IgG Fc region, is a classic feature of the disease with sensitivity of $60-80 \%$ [8], but its specificity is not very high since it can also be detected in other autoimmune diseases, such as systemic lupus erythematosus (SLE) and Sjogren's syndrome (SS). The key pathogenic markers are IgM and IgA rheumatoid factors in RA [2]. Showing perinuclear fluorescence, APF is probably an antibody of the 7S gammaglobulin type against keratohyalin granules in buccal mucosa cells and is high in RA patients compared to the healthy people [9]. AKA, a naturally occurring antibody that reacts with the keratinized tissue, is found in the serum of around 60\% RA patients but not in healthy people [10].

Autoantibodies induced by citrullination, conversion of peptidyl-arginine to peptidyl-citrulline, can be measured efficiently by using cyclic citrullinated peptides (CCP) as antigens $[11,12]$. The detection of anti-CCP antibodies, as well as RFs, particularly IgA-RF, has a strong predictive value for diagnosis in early RA $[12,13]$. Not only ESR but also anti-CCP is an important predictor of early bone mineral density loss [14].

Similar to RF, antibodies against citrullinated proteins (ACPA) have correlation with bone destruction, but the latter is associated with larger bone erosions by directly initiating the differentiation of bone-resorbing osteoclasts $[15,16]$. Moreover, the bone loss caused by ACPA occurs before disease onset in ACPA-positive patients [17, 18]. The knowledge on ACPA made great advancement in the field of RA in the past decade and this biomarker has already been included into the ACR/EULAR 2010 diagnostic criteria. Using both RF and ACPA may be helpful in diagnosis and classification of RA $[19,20]$. Furthermore, anti-mutated citrullinated vimentin (MCV) antibodies have been reported as a fairly sensitive serological marker of RA and were significantly higher in early RA patients [21].

2.2. CRP and ESR. In clinical management of RA, CRP and ESR are commonly ordered tests to guide diagnosis of RA besides the measurements of the mentioned autoantibodies. CRP is a protein, the levels of which rise in response to inflammation. Increased CRP was detected before the onset of RA [22] and also indicated the activity of the disease during the course of the disease. Erythrocyte sedimentation rate (ESR) is a nonspecific measure of inflammation and can be useful not only in diagnosing autoimmune diseases, such as rheumatoid arthritis, but also in monitoring the disease process. It can be an index observing the activity and severity of RA synovitis. The combination of ESR and CRP may improve sensitivity and specificity of the diagnosis of RA $[23,24]$.

2.3. Newly Found Clinical Biomarkers. What is more, levels of serum calreticulin (CRT) are now detected to be increased in patients with RA compared with those controls and have a significant correlation with disease activity in RA. It might be a potential clinical biomarker [25]. Likewise, there is an autoantibody system that discriminates between citrulline- and homocitrulline-containing antigens in the sera of RA patients. Anti-carbamylated protein (anti-CarP) antibodies $\operatorname{IgG}$ and $\operatorname{IgA}$ were observed in RA sera [26]. Interestingly, these anti-CarP antibodies are also present in around $20 \%$ of the ACPA-negative RA patients and have association with more severe joint damage, indicating they could serve as a unique and relevant serological marker for ACPA-negative RA [27].

Important associations between the above clinical markers and severity of RA have been noted and used in aiding diagnosis of RA, monitoring disease progress, and assessing prognostic in patients with established disease.

\section{Investigational Biomarkers}

Besides the clinically used biomarkers, scientists have been engaging in investigating potential biologic markers for many years. Cytokines serve as molecular messengers between cells and there are multiple studies revealing that numbers of cytokines have been involved in the pathogenesis of RA by triggering or regulating the inflammatory responses (Figure 1) [28, 29]. Overexpressions of certain cytokines, such as IL-1, IL-6, IL-8, IL-17, IL-21, tumor necrosis factor (TNF)- $\alpha$ and granulocyte-macrophage colony-stimulating factor (GM-CSF), were observed in RA patients [30-35]. These cytokines could promote synovial membrane inflammation and osteocartilaginous resorption via stimulation of osteoclastic mediators [35].

3.1. Th1, Th17 Cells and Related Cytokines. Autoreactive T cells, such as Thl and Th17 cells, are thought to play important roles in autoimmune pathology of RA [36-38]. The percentage of interferon (IFN)- $\gamma$ expressing cells was slightly increased in peripheral blood mononuclear cells (PBMC) but highly increased in synovial fluid mononuclear cell (SFMC) of RA patients [31]. IL-12, a Th1 cytokine, was increased in serum and synovial fluid in RA and its level correlated with disease activity score [39].

The discovery of Th17 cells enriched our knowledge and understanding of RA pathogenesis. Th17 profile therefore has shown pathogenic role in RA [40-42]. Increased IL-17 was reported in the sera and synovial fluid of RA patients [42-45]. Neutralizing IL-17 treatment reduced the severity and slowed the progression of collagen-induced arthritis 


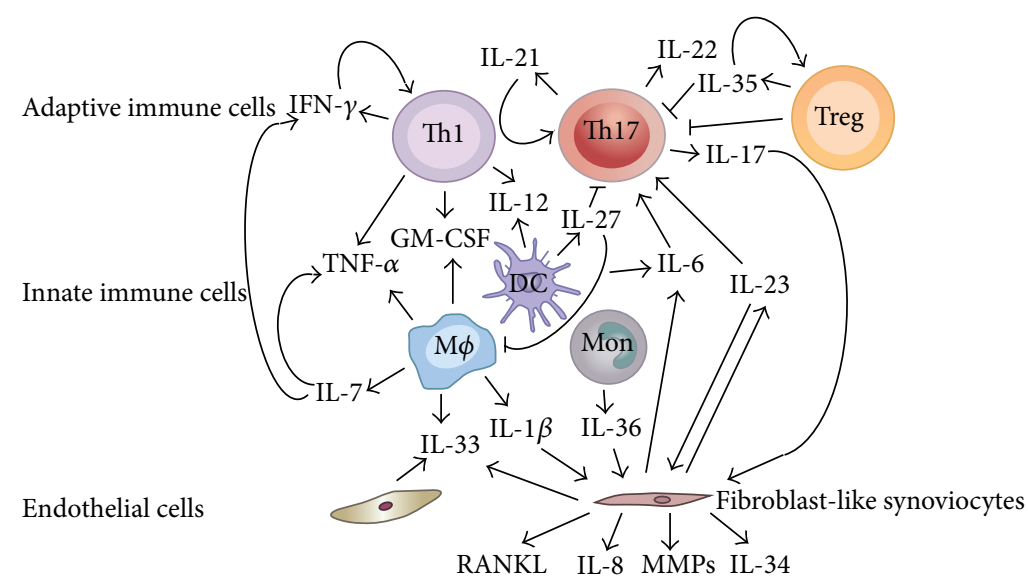

FIGURE 1: Network of investigational and prospective biomarkers in RA. A variety of different cell populations, including adaptive immune cells, innate immune cells, fibroblast-like synoviocytes, and endothelial cells, secrete cytokines as biomarkers not only in serum but also in synovial fluid and orchestrate inflammation and bone destruction in RA patients.

(CIA), a mouse model of human rheumatoid arthritis [46]. Secreted by Th17, IL-21 and IL-22 were also observed at a high level in RA patients compared to the healthy controls or osteoarthritis $(\mathrm{OA})$ patients [43, 47]. In addition, IL-21 autoregulated its own production in human $\mathrm{CD} 4+\mathrm{T}$ cells and enhanced Th17 proliferation, leading to the expression of RORC production, and was strongly associated with the levels of auto-antibodies and disease severity as well [31, 48]. IL-23 is known to promote IL-17 production [49] and was detected in RA synovial fibroblasts, but, like a loop, it can be upregulated by IL-17 in RA synovial fibroblasts via PI3-kinase/Akt-, NF$\kappa \mathrm{B}$-, and p38-MAPK-mediated pathways [50]. IL-23 directly induced osteoclast differentiation by upregulation of receptor activator of NF- $\kappa$ B (RANK) in mouse myeloid precursor cells and RANK ligand (RANKL) in human fibroblast-like synoviocytes [51, 52]. RANK/RNAKL signaling regulates the formation of multinucleated osteoclasts from their precursors as well as their activation and survival in normal bone remodeling and in a variety of pathologic conditions [53]. In RA synovial tissue, p19 subunit and RANKL have positive correlation and might contribute to bone destruction in RA $[54,55]$.

3.2. Other Proinflammatory Cytokines. IL-1 is produced by a variety of cells that are part of the innate system and mediates bone resorption and cartilage destruction. The IL- $1 \beta-N F-\kappa B$ axis is central in the production of proinflammatory mediators in the inflamed synovium $[56,57]$. NF- $\kappa \mathrm{B}$ activation by IL-1 $\beta$ induced the gene expressions of matrix metalloproteinases (MMPs) that are major products of cytokine stimulated fibroblast-like synovial cells (FLS) and efficiently degrade the collagenous components of cartilage and bone, leading to the joint deformity and pain in the patient with RA [58]. Additionally, proinflammatory cytokine, IL-6, has important effects on the differentiation and activation of $\mathrm{B}$ and $\mathrm{T}$ cells, macrophages, osteoclasts, chondrocytes, and endothelial cells and broad effects on hematopoiesis in the bone marrow [35].
Together with TGF- $\beta$, IL- 6 is the key inducer of Th17 via signal transducer and activation of transcription-3 (STAT-3) [59] and its level was significantly associated with clinical symptoms and levels of clinical biomarkers [60].

Additionally, TNF- $\alpha$ has shown its contribution to the pathogenesis of RA at early stage. It is produced locally in the joint by synovial macrophages and lymphocytes infiltrating the joint synovium. TNF has been recognized as a key pathogenic cytokine that drives a pathogenic cytokine milieu leading to tissue damage $[61,62]$.

3.3. Newly Emerged Cytokines/Chemokines. Other cytokines/ chemokines, such as IL-8, IL-9, IL-15, leukemia inhibitory factor (LIF), granulocyte colony-stimulating factor (G-CSF), chemoattractant protein-1 (MCP-1), growth-related oncogenes GRO- $\alpha$ and GRO- $\beta$, CCL19, CXCL12, and CXCL13, were upregulated in preclinical or clinical period of RA development by induction of IL-17 or TNF- $\alpha$ and IL-1 synergically $[4,5,63,64]$.

Therapeutic strategies that specifically block these investigational inflammatory cytokines are expected to be highly effective in treating RA patients. Actually, several immunotherapies have been developed and tested in RA treatment. The biological therapeutics include TNF inhibitors, IL-1 inhibitors, IL-6 inhibitors, and IL-17 inhibitors, as well as $\mathrm{B}$ cell depletion, costimulatory blockers, and JAK inhibitors $[20,35,65]$. On one hand these approaches neutralize the inflammatory mediators and show effectiveness in clinical trial; on the other hand, their effect can be evaluated by measuring the concentration of the inflammatory cytokines combined with clinical biomarkers, such as RF, ACPA, ESR, and CRP.

\section{Prospective Biomarkers}

Recently, several interleukins involved in inflammatory joint diseases have been identified and characterized [66] 
(Figure 1). These new biomarkers could give us more understanding of RA pathogenesis.

4.1. Pathogenic Cytokines. IL-7, which is an IL-2 cytokine family member, involves T cell-driven autoimmunity, inflammation, and tissue destruction $[67,68]$. The abundant intraarticular expression of IL-7 was detected in RA synovial fluid [69]. In addition, IL-7 and IL-7R were coexpressed on RA synovial tissue lining and sublining macrophages and endothelial cells [70]. This cytokine can stimulate TNF- $\alpha$ and IFN- $\gamma$ production and its level correlates with disease activity, suggesting it has value as a diagnostic biomarker predicting the progression to RA $[71,72]$.

The overproduction of IL-33, a newly identified inflammatory cytokine, was found in synovial fluids of RA patients. It could be upregulated by hypoxia-inducible factor- $1 \alpha$ (HIF$1 \alpha$ ) which was also increased in RA synovium through the activation of p38 and ERK pathways. And IL-33 in turn induced more HIF- $1 \alpha$ in RA. These two participants exacerbate the disease severity and may serve as new therapeutic targets in biologic treatment [73].

IL-34, expressed by giant cell tumours of bone, plays a critical role in macrophage differentiation and osteoclastogenesis [74, 75]. In RA patients, it was elevated in synovium, synovial fluid (SF), and FLS. The secretion of IL34 was upregulated in FLS by TNF- $\alpha$ or IL-1 $\beta$ induction and was mediated by the transcription factor nuclear factor $\kappa \mathrm{B}$ $(\mathrm{NF}-\kappa \mathrm{B})$ and activation of c-Jun N-terminal kinase (JNK), indicating its osteoclastogenic role in RA $[76,77]$.

Increased IL-36 $\alpha$ (one form of IL-36) expression was found in RA synovium and could lead to IL-6 and IL-8 production by synovial fibroblasts through $\mathrm{p} 38 / \mathrm{NF} \kappa \mathrm{B}$ activation in vitro [78]. IL-36 $\beta$, known as IL-1F8, was found to be expressed in synovial membrane in CIA and synovial membrane biopsies from RA patients [66, 79]. Another member of IL-1 family which was detected in various inflammatory diseases including RA is IL-37 which interacted intracellularly with Smad3 [66, 80].

4.2. Anti-Inflammatory Cytokines. In contrast to the inflammatory cytokines, IL-35 is an inhibitory cytokine that contributes to regulatory $\mathrm{T}$ (Treg) cells function and suppresses the pathogenic cells, such as Th1 and Th17 cells [55, 81, 82]. IL-35 belongs to IL-12 family and is mainly produced by CD4+Foxp3+Treg cells $[55,83]$. It can further enhance Treg generation, suggesting that it is an autocrine cytokine [84]. IL-35 treatment could ameliorate the severity of CIA [81, 82].

IL-27 is a novel member of IL-12 family and has two sides' properties, pro- or anti-inflammatory in RA [85]. Significantly higher concentration of IL-27 was found in plasma and synovial fluid of RA patients than in OA patients [86, 87]. Expressions of ICAM-1, vascular cell adhesion molecule, inflammatory chemokines, such as IL-6, CCL2, CXCL9, CXCL10, and MMP-1, in RA FLS were induced under IL-27 stimulation [85]. Although IL-27 shows its pathogenic role, it was also found to have suppressive function in macrophage responses to TNF- $\alpha$ and IL-1 $\beta$ [88]. Furthermore, IL-27 also promotes $\mathrm{CD} 4+\mathrm{Foxp} 3-\mathrm{T}$ regulatory cell to produce
IL-10 and downregulate IL-6 and IL-1 $\beta$ in early CIA, which resulted in suppression of Th17 and monocyte migration and vascularization $[89,90]$.

Although numerous studies revealed the new candidates participating in development of RA, their exact mechanisms by which these molecules modulate the proinflammatory or anti-inflammatory response still require elucidation. These emerging players not only give us new evidences in complicated pathogenesis of RA but also suggest new strategies of therapeutic intervention in RA since current biotherapies are not effective for all RA patients.

\section{Conclusion}

RA is a chronic and systemic autoimmune disease that affects many tissues and organs, especially flexible joints. It can lead to deformity and dysfunction if not timely and adequately treated. Biomarkers, not only already clinically used but also under investigation, play important roles in the development of chronic human diseases which include RA. They may serve as indicators for clinical observation on the disease progression and the therapeutic effect. Furthermore, some of the biomarkers can also be or has already been a therapeutic target for the treatment. We expect that targeting specific biomarkers with the least side effects will bring hope to RA patients.

\section{Conflict of Interests}

The authors have no conflict of interests to declare. The authors alone are responsible for the content and writing of the paper.

\section{Acknowledgments}

This work was supported by Grants from the National Science Foundation of China (NSFC-81373208 and 81302569), Shanghai Commission of Science and Technology (11JC1411602, 12ZR1448600), Shanghai Municipal Education Commission (12ZZ103, 14YZ042), and Shanghai Board of Health Foundation $(2011177,20124196)$.

\section{References}

[1] M. Feldmann, F. M. Brennan, and R. N. Maini, "Rheumatoid arthritis," Cell, vol. 85, no. 3, pp. 307-310, 1996.

[2] D. L. Scott, F. Wolfe, and T. W. J. Huizinga, "Rheumatoid arthritis," The Lancet, vol. 376, no. 9746, pp. 1094-1108, 2010.

[3] D. Aletaha, T. Neogi, and A. J. Silman, "2010 rheumatoid arthritis classification criteria: an American College of Rheumatology/European League Against Rheumatism collaborative initiative," Annals of the Rheumatic Diseases, vol. 69, no. 10, p. 1892, 2010.

[4] J. M. Hughes-Austin, K. D. Deane, L. A. Derber et al., "Multiple cytokines and chemokines are associated with rheumatoid arthritis-related autoimmunity in first-degree relatives without rheumatoid arthritis: studies of the Aetiology of Rheumatoid Arthritis (SERA)," Annals of the Rheumatic Diseases, vol. 72, no. 6, pp. 901-907, 2013. 
[5] K. D. Deane, C. I. O’Donnell, W. Hueber et al., "The number of elevated cytokines and chemokines in preclinical seropositive rheumatoid arthritis predicts time to diagnosis in an agedependent manner," Arthritis and Rheumatism, vol. 62, no. 11, pp. 3161-3172, 2010.

[6] H. Kokkonen, I. Söderström, J. Rocklöv et al., "Up-regulation of cytokines and chemokines predates the onset of rheumatoid arthritis," Arthritis and Rheumatology, vol. 62, pp. 383-391, 2010.

[7] R. Goldbach-Mansky, J. Lee, A. McCoy et al., "Rheumatoid arthritis associated autoantibodies in patients with synovitis of recent onset," Arthritis Research, vol. 2, no. 3, pp. 236-243, 2000.

[8] S. Bas, T. V. Perneger, M. Seitz, J. Tiercy, P. Roux-Lombard, and P. A. Guerne, "Diagnostic tests for rheumatoid arthritis: comparison of anti-cyclic citrullinated peptide antibodies, antikeratin antibodies and IgM rheumatoid factors," Rheumatology, vol. 41, no. 7, pp. 809-814, 2002.

[9] R. L. Nienhuis and E. Mandema, "A new serum factor in patients with rheumatoid arthritis; the antiperinuclear factor," Annals of the Rheumatic Diseases, vol. 23, pp. 302-305, 1964.

[10] B. J. Young, R. K. Mallya, R. D. Leslie, C. J. Clark, and T. J. Hamblin, "Anti-keratin antibodies in rheumatoid arthritis," The British Medical Journal, vol. 2, no. 6182, pp. 297-299, 1979.

[11] W. J. van Venrooij and G. J. M. Pruijn, "Citrullination: a small change for a protein with great consequences for rheumatoid arthritis," Arthritis Research, vol. 2, no. 4, pp. 249-251, 2000.

[12] S. Rantapää-Dahlqvist, B. A. W. de Jong, E. Berglin et al., "Antibodies against cyclic citrullinated peptide and IgA rheumatoid factor predict the development of rheumatoid arthritis," Arthritis and Rheumatism, vol. 48, no. 10, pp. 2741-2749, 2003.

[13] H. Visser, S. Le Cessie, K. Vos, F. C. Breedveld, and J. M. W. Hazes, "How to diagnose rheumatoid arthritis early: a prediction model for persistent (erosive) arthritis," Arthritis and Rheumatism, vol. 46, no. 2, pp. 357-365, 2002.

[14] P. Bøyesen, M. Hoff, S. Odegård et al., "Antibodies to cyclic citrullinated protein and erythrocyte sedimentation rate predict hand bone loss in patients with rheumatoid arthritis of short duration: a longitudinal study," Arthritis Research and Therapy, vol. 11, no. 4, article R103, 2009.

[15] U. Harre, D. Georgess, H. Bang et al., "Induction of osteoclastogenesis and bone loss by human autoantibodies against citrullinated vimentin," Journal of Clinical Investigation, vol. 122, no. 5, pp. 1791-1802, 2012.

[16] A. Kleyer, S. Finzel, J. Rech et al., "Bone loss before the clinical onset of rheumatoid arthritis in subjects with anticitrullinated protein antibodies," Annals of the Rheumatic Diseases, vol. 73, pp. 854-860, 2014.

[17] R. Kocijan, U. Harre, and G. Schett, "ACPA and Bone Loss in Rheumatoid Arthritis," Current Rheumatology Reports, vol. 15, article 366, 2013.

[18] Y. Saeki, E. Kudo-Tanaka, S. Ohshima et al., "Baseline anticitrullinated peptide antibody (ACPA) titers and serum interleukin-6 (IL-6) levels possibly predict progression of bone destruction in early stages of rheumatoid arthritis (ERA)," Rheumatology International, vol. 33, no. 2, pp. 451-456, 2013.

[19] K. P. Liao, M. E. Weinblatt, and D. H. Solomon, "The end of rheumatoid factor as we know it?" Arthritis and Rheumatism, vol. 63, no. 5, pp. 1170-1172, 2011.

[20] S. Modi, M. Soejima, and M. C. Levesque, "The effect of targeted rheumatoid arthritis therapies on anti-citrullinated protein autoantibody levels and B cell responses," Clinical and Experimental Immunology, vol. 173, no. 1, pp. 8-17, 2013.
[21] X. Liu, R. Jia, J. Zhao, and Z. Li, "The role of anti-mutated citrullinated vimentin antibodies in the diagnosis of early rheumatoid arthritis," Journal of Rheumatology, vol. 36, no. 6, pp. 1136-1142, 2009.

[22] M. M. J. Nielen, D. van Schaardenburg, H. W. Reesink et al., "Increased levels of C-reactive protein in serum from blood donors before the onset of rheumatoid arthritis," Arthritis and Rheumatism, vol. 50, no. 8, pp. 2423-2427, 2004.

[23] N. A. Shadick, N. R. Cook, E. W. Karlson et al., "C-reactive protein in the prediction of rheumatoid arthritis in women," Archives of Internal Medicine, vol. 166, no. 22, pp. 2490-2494, 2006.

[24] C. Barnabe, J. Xiong, J. E. Pope et al., "Factors associated with time to diagnosis in early rheumatoid arthritis," Rheumatology International, vol. 34, pp. 85-92, 2014.

[25] M. Ni, W. Wei, Y. Wang et al., "Serum levels of calreticulin in correlation with disease activity in patients with rheumatoid arthritis," Journal of Clinical Immunology, vol. 33, no. 5, pp. 947953, 2013

[26] J. Shi, R. Knevel, P. Suwannalai et al., "Autoantibodies recognizing carbamylated proteins are present in sera of patients with rheumatoid arthritis and predict joint damage," Proceedings of the National Academy of Sciences of the United States of America, vol. 108, no. 42, pp. 17372-17377, 2011.

[27] A. Willemze, R. E. M. Toes, T. W. J. Huizinga, and L. A. Trouw, "New biomarkers in rheumatoid arthritis," Netherlands Journal of Medicine, vol. 70, no. 9, pp. 392-399, 2012.

[28] I. B. McInnes and G. Schett, "The pathogenesis of rheumatoid arthritis," The New England Journal of Medicine, vol. 365, no. 23, pp. 2205-2219, 2011.

[29] A. Burska, M. Boissinot, and F. Ponchel, "Cytokines as biomarkers in rheumatoid arthritis," Mediators of Inflammation, vol. 2014, Article ID 545493, 24 pages, 2014.

[30] K. T. Jørgensen, A. Wiik, M. Pedersen et al., "Cytokines, autoantibodies and viral antibodies in premorbid and postdiagnostic sera from patients with rheumatoid arthritis: case-control study nested in a cohort of Norwegian blood donors," Annals of the Rheumatic Diseases, vol. 67, no. 6, pp. 860-866, 2008.

[31] X. Niu, D. He, X. Zhang et al., "IL-21 regulates Th17 cells in rheumatoid arthritis," Human Immunology, vol. 71, no. 4, pp. 334-341, 2010.

[32] X. Niu, D. He, S. Deng et al., "Regulatory immune responses induced by IL-1 receptor antagonist in rheumatoid arthritis," Molecular Immunology, vol. 49, no. 1-2, pp. 290-296, 2011.

[33] D. O’ Gradaigh, D. Ireland, S. Bord, and J. E. Compston, "Joint erosion in rheumatoid arthritis: Interactions between tumour necrosis factor $\alpha$, interleukin 1 , and receptor activator of nuclear factor $\kappa \mathrm{B}$ ligand (RANKL) regulate osteoclasts," Annals of the Rheumatic Diseases, vol. 63, no. 4, pp. 354-359, 2004.

[34] R. N. Maini and P. C. Taylor, "Anti-cytokine therapy for rheumatoid arthritis," Annual Review of Medicine, vol. 51, pp. 207-229, 2000.

[35] G. Chen, "Immunotherapy of rheumatoid arthritis targeting inflammatory cytokines and autoreactive T cells," Archivum Immunologiae et Therapiae Experimentalis, vol. 58, no. 1, pp. 2736, 2010.

[36] C. Dong and R. A. Flavell, "Cell fate decision: T-helper 1 and subsets in immune responses," Arthritis Research, vol. 2, no. 3, pp. 179-188, 2000.

[37] L. E. Harrington, R. D. Hatton, P. R. Mangan et al., "Interleukin 17-producing $\mathrm{CD}^{+}$effector T cells develop via a lineage distinct 
from the T helper type 1 and 2 lineages," Nature Immunology, vol. 6, no. 11, pp. 1123-1132, 2005.

[38] H. Park, Z. Li, X. O. Yang et al., "A distinct lineage of CD4 T cells regulates tissue inflammation by producing interleukin 17," Nature Immunology, vol. 6, no. 11, pp. 1133-1141, 2005.

[39] L. Petrovic-Rackov and N. Pejnovic, "Clinical significance of IL-18, IL-15, IL-12 and TNF- $\alpha$ measurement in rheumatoid arthritis," Clinical Rheumatology, vol. 25, no. 4, pp. 448-452, 2006.

[40] E. Lubberts, L. A. B. Joosten, B. Oppers et al., "IL-1-independent role of IL-17 in synovial inflammation and joint destruction during collagen-induced arthritis," The Journal of Immunology, vol. 167, no. 2, pp. 1004-1013, 2001.

[41] E. Lubberts, "IL-17/Th17 targeting: on the road to prevent chronic destructive arthritis?” Cytokine, vol. 41, no. 2, pp. 8491, 2008.

[42] N. Qu, M. Xu, I. Mizoguchi et al., "Pivotal roles of T-helper 17-related cytokines, IL-17, IL-22, and IL-23, in inflammatory diseases," Clinical and Developmental Immunology, vol. 2013, Article ID 968549, 13 pages, 2013.

[43] M. Chabaud, J. M. Durand, N. Buchs et al., "Human interleukin17: a T cell-derived proinflammatory cytokine produced by the rheumatoid synovium," Arthritis and Rheumatology, vol. 42, pp. 963-970, 1999.

[44] M. Ziolkowska, A. Koc, G. Luszczykiewicz et al., "High levels of IL-17 in rheumatoid arthritis patients: IL-15 triggers in vitro IL17 production via cyclosporin A-sensitive mechanism," Journal of Immunology, vol. 164, no. 5, pp. 2832-2838, 2000.

[45] S. Hwang and H. Kim, "Expression of IL-17 homologs and their receptors in the synovial cells of rheumatoid arthritis patients," Molecules and Cells, vol. 19, no. 2, pp. 180-184, 2005.

[46] E. Lubberts, M. I. Koenders, B. Oppers-Walgreen et al., "Treatment with a neutralizing anti-murine interleukin-17 antibody after the onset of collagen-induced arthritis reduces joint inflammation, cartilage destruction, and bone erosion," Arthritis and Rheumatism, vol. 50, no. 2, pp. 650-659, 2004.

[47] H. Ikeuchi, T. Kuroiwa, N. Hiramatsu et al., "Expression of interleukin-22 in rheumatoid arthritis: potential role as a proinflammatory cytokine," Arthritis and Rheumatism, vol. 52, no. 4, pp. 1037-1046, 2005.

[48] S. Zivojinovic, N. Pejnovic, M. Sefik-Bukilica et al., "Effects of TNF inhibitor on innate inflammatory and Thl7 cytokines in stimulated whole blood from rheumatoid arthritis patients," Inflammopharmacology, vol. 20, no. 6, pp. 323-330, 2012.

[49] S. Aggarwal, N. Ghilardi, M. Xie, F. J. De Sauvage, and A. L. Gurney, "Interleukin-23 promotes a distinct CD4 T cell activation state characterized by the production of interleukin17," The Journal of Biological Chemistry, vol. 278, no. 3, pp. 19101914, 2003.

[50] H. R. Kim, M. L. Cho, K. W. Kim et al., "Up-regulation of IL23p19 expression in rheumatoid arthritis synovial fibroblasts by IL-17 through PI3-kinase-, NF- $\kappa$ B- and p38 MAPK-dependent signalling pathways," Rheumatology, vol. 46, no. 1, pp. 57-64, 2007.

[51] L. Chen, X. Q. Wei, B. Evans, W. Jiang, and D. Aeschlimann, "IL23 promotes osteoclast formation by up-regulation of receptor activator of NF- $\kappa \mathrm{B}$ (RANK) expression in myeloid precursor cells," European Journal of Immunology, vol. 38, no. 10, pp. 28452854, 2008.

[52] X. Li, K. Kim, M. Cho et al., "IL-23 induces receptor activator of NF- $\kappa \mathrm{B}$ ligand expression in fibroblast-like synoviocytes via
STAT3 and NF- $\kappa$ B signal pathways," Immunology Letters, vol. 127, no. 2, pp. 100-107, 2010.

[53] B. F. Boyce and L. Xing, "Biology of RANK, RANKL, and osteoprotegerin," Arthritis Research and Therapy, vol. 9, no. 1, article S1, 2007.

[54] K. Sato, A. Suematsu, K. Okamoto et al., “Th17 functions as an osteoclastogenic helper $\mathrm{T}$ cell subset that links T cell activation and bone destruction," Journal of Experimental Medicine, vol. 203, no. 12, pp. 2673-2682, 2006.

[55] R. M. Pope and S. Shahrara, "Possible roles of IL-12-family cytokines in rheumatoid arthritis," Nature Reviews Rheumatology, vol. 9, no. 4, pp. 252-256, 2013.

[56] M. H. Schiff, "Role of interleukin 1 and interleukin 1 receptor antagonist in the mediation of rheumatoid arthritis," Annals of the Rheumatic Diseases, vol. 59, no. 1, pp. i103-i108, 2000.

[57] Y. Lee, S. Kweon, K. Kwon, J. Park, T. Yoon, and B. Park, "Inhibition of IL-1 $\beta$-mediated inflammatory responses by the $\mathrm{I} \kappa \mathrm{B} \alpha$ super-repressor in human fibroblast-like synoviocytes," Biochemical and Biophysical Research Communications, vol. 378, no. 1, pp. 90-94, 2009.

[58] M. P. Vincenti, C. I. Coon, and C. E. Brinckerhoff, "Nuclear factor kappaB/p50 activates an element in the distal matrix metalloproteinase 1 promoter in interleukin-lbeta-stimulated synovial fibroblasts," Arthritis and Rheumatology, vol. 41, pp. 1987-1994, 1998.

[59] X. O. Yang, A. D. Panopoulos, R. Nurieva et al., "STAT3 regulates cytokine-mediated generation of inflammatory helper T cells," Journal of Biological Chemistry, vol. 282, no. 13, pp. 9358-9363, 2007.

[60] J. Wang, A. Platt, R. Upmanyu et al., "IL-6 pathway-driven investigation of response to IL-6 receptor inhibition in rheumatoid arthritis," BMJ Open, vol. 3, no. 8, Article ID e003199, 2013.

[61] E. H. S. Choy and G. S. Panayi, "Cytokine pathways and joint inflamation in rheumatoid arthritis," New England Journal of Medicine, vol. 344, no. 12, pp. 907-916, 2001.

[62] G. Harriman, L. K. Harper, and T. F. Schaible, "Summary of clinical trials in rheumatoid arthritis using infliximab, an antiTNF $\alpha$ treatment," Annals of the Rheumatic Diseases, vol. 58, no. 1, pp. I61-I64, 1999.

[63] M. I. Koenders, E. Lubberts, F. A. J. van de Loo et al., "Interleukin-17 acts independently of TNF- $\alpha$ under arthritic conditions," Journal of Immunology, vol. 176, no. 10, pp. 62626269, 2006.

[64] J. Sellam, S. Rouanet, H. Hendel-Chavez et al., "CCL19, a B cell chemokine, is related to the decrease of blood memory B cells and predicts the clinical response to rituximab in patients with rheumatoid arthritis," Arthritis and Rheumatism, vol. 65, no. 9, pp. 2253-2261, 2013.

[65] J. R. Curtis and J. A. Singh, "Use of biologics in rheumatoid arthritis: current and emerging paradigms of care," Clinical Therapeutics, vol. 33, no. 6, pp. 679-707, 2011.

[66] G. Clavel, A. Thiolat, and M. Boissier, "Interleukin newcomers creating new numbers in rheumatology: IL-34 to IL-38," Joint Bone Spine, vol. 80, no. 5, pp. 449-453, 2013.

[67] X. S. Wang, B. Z. Li, L. F. Hu et al., "Perspectives of the relationship between IL-7 and autoimmune diseases," Clinical Rheumatology, vol. 32, pp. 1703-1709, 2013.

[68] A. Bikker, C. E. Hack, F. P. J. G. Lafeber, and J. A. G. van Roon, "Interleukin-7: a key mediator in T cell-driven autoimmunity, inflammation, and tissue destruction," Current Pharmaceutical Design, vol. 18, no. 16, pp. 2347-2356, 2012. 
[69] J. A. G. Van Roon, M. C. Verweij, M. W. Wijk, K. M. G. Jacobs, J. W. J. Bijlsma, and F. P. J. G. Lafeber, "Increased intraarticular interleukin-7 in rheumatoid arthritis patients stimulates cell contact-depedent activation of $\mathrm{CD}^{+}$T cells and macrophages," Arthritis and Rheumatism, vol. 52, no. 6, pp. 1700-1710, 2005.

[70] S. R. Pickens, N. D. Chamberlain, M. V. Volin et al., "Characterization of interleukin-7 and interleukin-7 receptor in the pathogenesis of rheumatoid arthritis," Arthritis and Rheumatism, vol. 63, no. 10, pp. 2884-2893, 2011.

[71] J. A. G. Van Roon, K. A. F. M. Glaudemans, J. W. J. Bijilsma, and F. P. J. G. Lafeber, "Interleukin 7 stimulates tumour necrosis factor $\alpha$ and Th 1 cytokine production in joints of patients with rheumatoid arthritis," Annals of the Rheumatic Diseases, vol. 62, no. 2, pp. 113-119, 2003.

[72] V. Goëb, P. Aegerter, R. Parmar et al., "Progression to rheumatoid arthritis in early inflammatory arthritis is associated with low IL-7 serum levels," Annals of the Rheumatic Diseases, vol. 72, no. 6, pp. 1032-1036, 2013.

[73] F. Hu, L. Shi, R. Mu et al., "Hypoxia-inducible factor- $1 \alpha$ and interleukin 33 form a regulatory circuit to perpetuate the inflammation in rheumatoid arthritis," PLoS ONE, vol. 8, Article ID e72650, 2013.

[74] M. Baud'Huin, R. Renault, C. Charrier et al., "Interleukin-34 is expressed by giant cell tumours of bone and plays a key role in RANKL-induced osteoclastogenesis," Journal of Pathology, vol. 221, no. 1, pp. 77-86, 2010.

[75] Z. Chen, K. Buki, J. Vääräniemi, G. Gu, and H. K. Väänänen, "The critical role of IL-34 in osteoclastogenesis," PLoS ONE, vol. 6, no. 4, Article ID e18689, 2011.

[76] S. Hwang, B. Choi, S. Kang et al., "Interleukin-34 produced by human fibroblast-like synovial cells in rheumatoid arthritis supports osteoclastogenesis," Arthritis Research and Therapy, vol. 14, no. 1, article R14, 2012.

[77] M. Chemel, B. le Goff, R. Brion et al., "Interleukin 34 expression is associated with synovitis severity in rheumatoid arthritis patients," Annals of the Rheumatic Diseases, vol. 71, no. 1, pp. 150-154, 2012.

[78] S. Frey, A. Derer, M. Messbacher et al., "The novel cytokine interleukin-36 $\alpha$ is expressed in psoriatic and rheumatoid arthritis synovium," Annals of the Rheumatic Diseases, vol. 72, no. 9, pp. 1569-1574, 2013.

[79] D. Magne, G. Palmer, J. L. Barton et al., "The new IL-1 family member IL-1F8 stimulates production of inflammatory mediators by synovial fibroblasts and articular chondrocytes," Arthritis Research and Therapy, vol. 8, no. 3, article R80, 2006.

[80] M. F. Nold, C. A. Nold-Petry, J. A. Zepp, B. E. Palmer, P. Bufler, and C. A. Dinarello, "IL-37 is a fundamental inhibitor of innate immunity," Nature Immunology, vol. 11, no. 11, pp. 1014-1022, 2010.

[81] W. Niedbala, X. Q. Wei, B. Cai et al., "IL-35 is a novel cytokine with therapeutic effects against collagen-induced arthritis through the expansion of regulatory T cells and suppression of Th17 cells," European Journal of Immunology, vol. 37, no. 11, pp. 3021-3029, 2007.

[82] I. Kochetkova, S. Golden, K. Holderness, G. Callis, and D. W. Pascual, "IL-35 stimulation of $\mathrm{CD}^{2} 9^{+}$regulatory $\mathrm{T}$ cells confers protection against collagen II-induced arthritis via the production of IL-10," The Journal of Immunology, vol. 184, no. 12, pp. 7144-7153, 2010.

[83] L. W. Collison, C. J. Workman, T. T. Kuo et al., "The inhibitory cytokine IL-35 contributes to regulatory T-cell function," Nature, vol. 450, no. 7169, pp. 566-569, 2007.
[84] L. W. Collison, V. Chaturvedi, A. L. Henderson et al., "IL-35mediated induction of a potent regulatory T cell population," Nature Immunology, vol. 11, no. 12, pp. 1093-1101, 2010.

[85] F. Gong, Y. Pan, X. Huang, J. Chen, J. Xiao, and H. Zhu, "Interleukin-27 as a potential therapeutic target for rheumatoid arthritis: has the time come?" Clinical Rheumatology, vol. 32, no. 10, pp. 1425-1428, 2013.

[86] C. K. Wong, D. P. Chen, L. S. Tam, E. K. Li, Y. B. Yin, and C. W. K. Lam, "Effects of inflammatory cytokine IL-27 on the activation of fibroblast-like synoviocytes in rheumatoid arthritis," Arthritis Research and Therapy, vol. 12, article R129, 2010.

[87] S. Tanida, H. Yoshitomi, M. Ishikawa et al., "IL-27-producing $\mathrm{CD}_{14}{ }^{+}$cells infiltrate inflamed joints of rheumatoid arthritis and regulate inflammation and chemotactic migration," Cytokine, vol. 55, no. 2, pp. 237-244, 2011.

[88] G. D. Kalliolias, R. A. Gordon, and L. B. Ivashkiv, "Suppression of TNF- $\alpha$ and IL-1 signaling identifies a mechanism of homeostatic regulation of macrophages by IL-27," Journal of Immunology, vol. 185, no. 11, pp. 7047-7056, 2010.

[89] E. D. T. Wojno and C. A. Hunter, "New directions in the basic and translational biology of interleukin-27," Trends in Immunology, vol. 33, no. 2, pp. 91-97, 2012.

[90] S. R. Pickens, N. D. Chamberlain, M. V. Volin et al., "Local expression of interleukin-27 ameliorates collagen-induced arthritis," Arthritis \& Rheumatism, vol. 63, no. 8, pp. 2289-2298, 2011. 




The Scientific World Journal
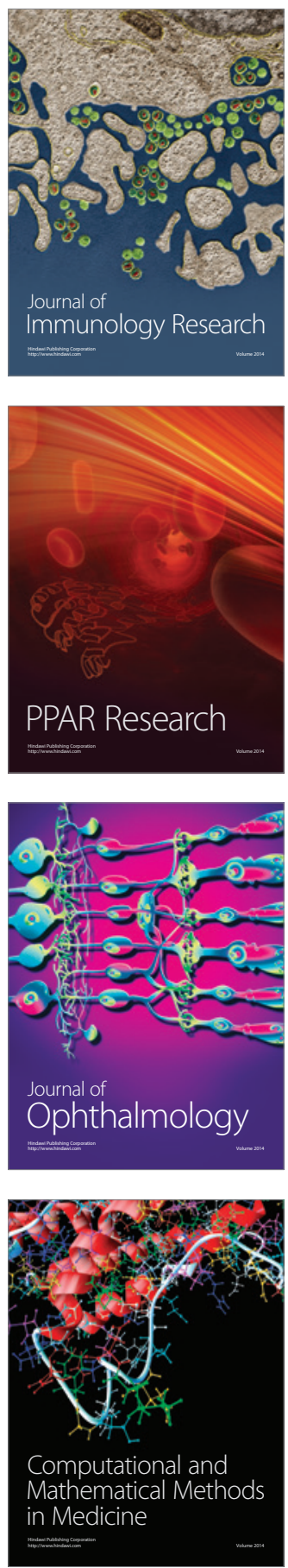



Gastroenterology

Research and Practice
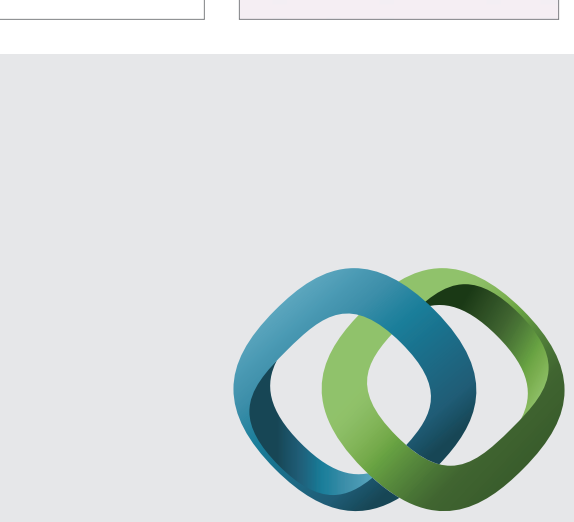

\section{Hindawi}

Submit your manuscripts at

http://www.hindawi.com
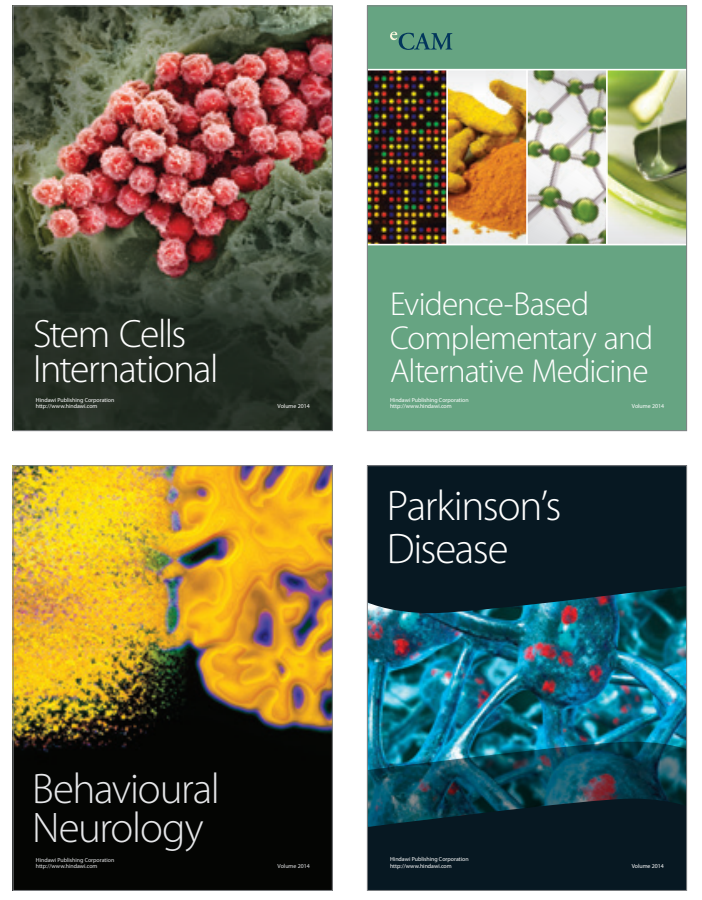
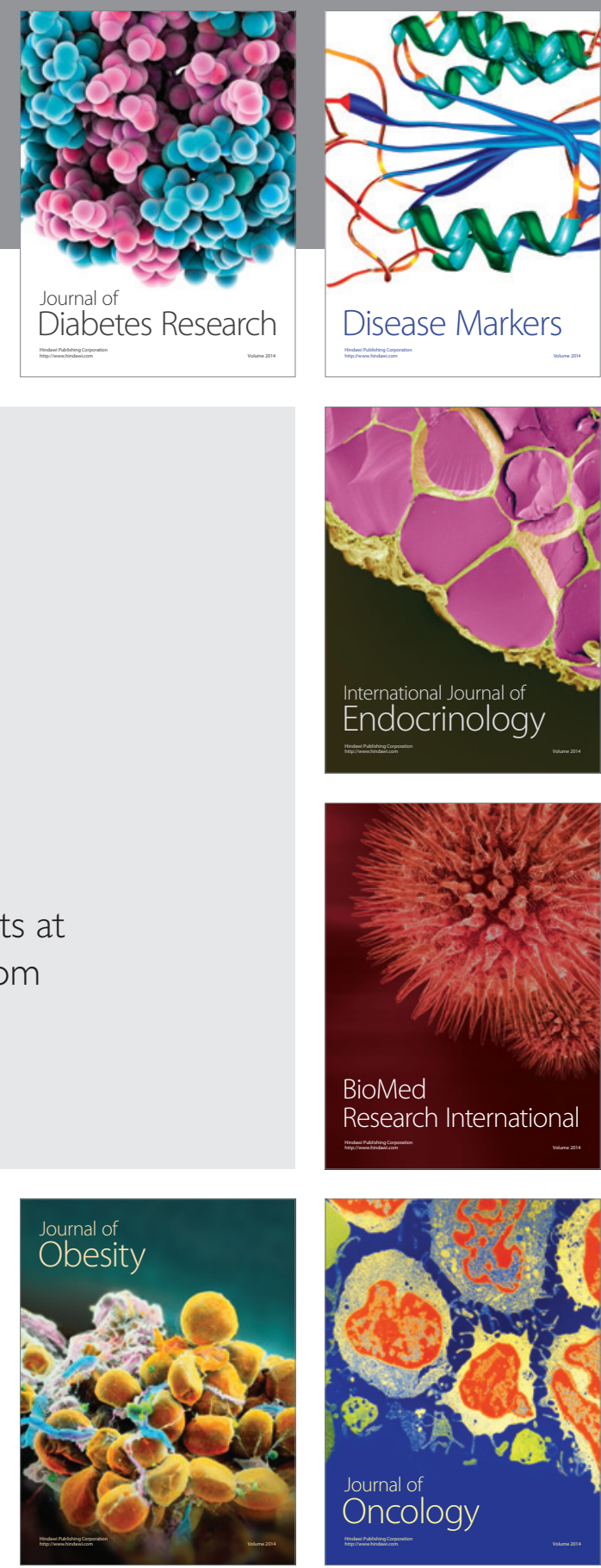

Disease Markers
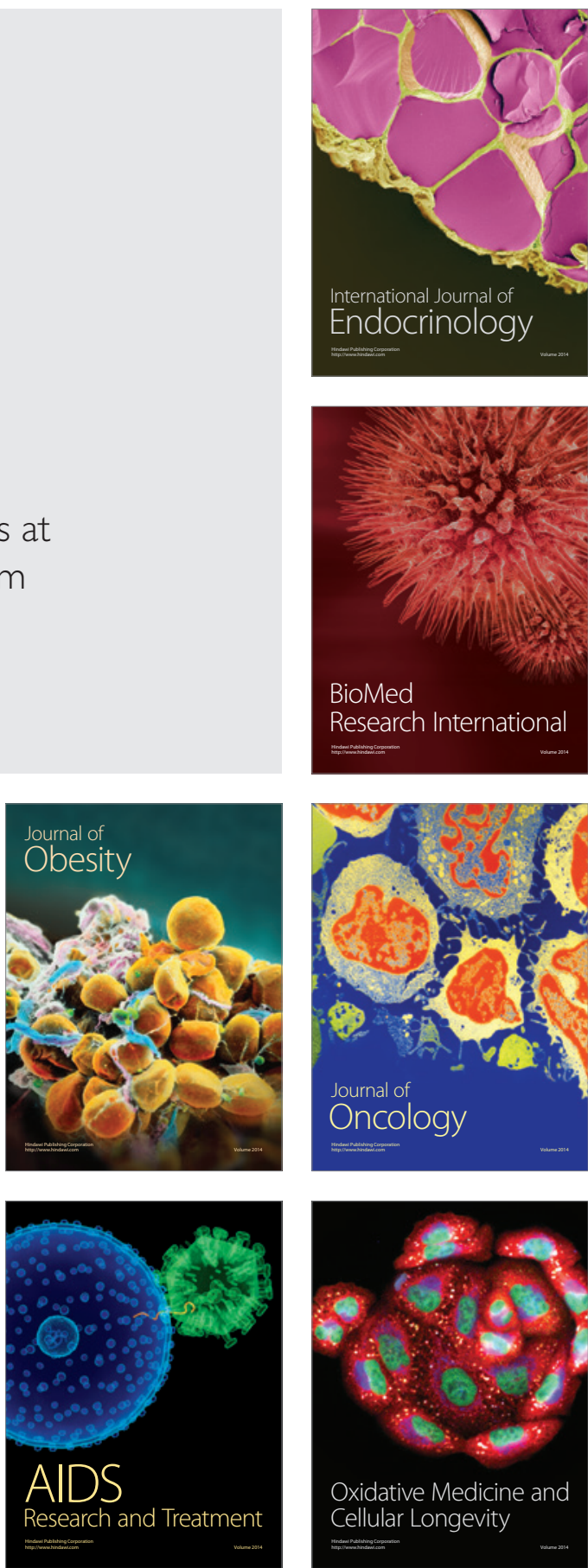